\title{
Environmental issues caused by the increasing number of vehicles in Iraq
}

\author{
H. M. Jassim ${ }^{1}$, F. H. Ibraheem ${ }^{2}$ \& B. F. A. Zangana ${ }^{3}$ \\ ${ }^{1}$ Geotechnical Engineering Department, \\ Faculty of Engineering, Koya University, Iraq \\ ${ }^{2}$ Chemical Engineering Department, \\ Faculty of Engineering, Koya University, Iraq \\ ${ }^{3}$ Petroleum Engineering Department, \\ Faculty of Engineering, Koya University, Iraq
}

\begin{abstract}
Iraq has witnessed a big challenge in the environmental issues due to the big increase in the production of various types of pollutants.

We will try in this research to shed light on the pollutants produced by the increasing number of registered and used vehicles in Iraq.

We have depended on extensive statistics published by the Ministry of Planning on the increasing numbers of registered and used vehicles (both gasoline and diesel types) classified according to each governorate in Iraq between 2007 and 2013. Studies of the environmental effects of such increase have been made, whereby statistics of the polluting gases $\left(\mathrm{CO}, \mathrm{CO}_{2}, \mathrm{NO}_{\mathrm{x}}\right.$, and $\left.\mathrm{HC}\right)$ and mass particulates were prepared, analysed and represented graphically in a comparable manner.

The results of this research revealed the following results: An increase in the number of vehicles by $437 \%$ from 2007 to 2013 . This was accompanied by an increase in the amount of daily pollutants ( $\mathrm{NOx}, \mathrm{CO}, \mathrm{HC}$ and particulate mass) excluding $\mathrm{CO}_{2}$ from 441 tons/day in 2007 to 1913 tons/day in 2013 and an increase of $\mathrm{CO}_{2}$ from 6068 tons/day in 2007 to 27382 tons/day in 2013.

Keywords: air pollution, carbon dioxide, carbon monoxide, contaminant, environmental issues, hazardous, mass particulate, nitrogen oxides, pollutant.
\end{abstract}




\section{Introduction}

Iraq has a strategic location in the Middle East. Due to the continental climate and the normal elevation, Iraq has hot summer and cold winters [1]. A lot of sites in Iraq can be regarded as high density traffic sites especially in the capital Baghdad. An excess of pollution and high levels of emission of various pollutants due various reasons are produced. One of the major reasons is pollution due to automobile fuel consumption which led to a negative impact on the economy and environment [2-4].

An overview of the conditions of all Iraqi governorates and comparing them with the conditions years before will indicate vast development, especially in the fields of transportation. We also noticed that the population has grown dramatically in addition to a huge increase of the numbers of vehicles as well as the big increase in gasoline and diesel consumption with accompanying pollutants emissions as being the sources of air pollution in these cities.

We believe that understanding the impact of environmental issues is still not fully recognized in Iraq in addition to the shortcomings of doing enough research dealing with the environment and environmental protection.

\section{Rate of growth of automobiles}

The automobiles market in Iraq has witnessed a large increase in the numbers of automobiles which are registered and used during the past few years [5]. This will be reflected on the amount of pollution connected with such increase [6], as shown in table 1 below. The authors published two papers on pollution issues of automobiles in Erbil City [7] and in Kurdistan Region [8].

Table 1: Accumulated automobile profile in Iraq through the period from 2007-2013.

\begin{tabular}{|c|c|c|c|c|c|c|}
\hline Year & Nineveh & Kirkuk & Diala & Anbar & Baghdad & Babylon \\
\hline 2007 & 88260 & 32099 & 43722 & 53891 & 374875 & 49895 \\
\hline 2008 & 94903 & 34516 & 47013 & 57947 & 403092 & 53651 \\
\hline 2009 & 102046 & 37114 & 50552 & 62309 & 433432 & 57689 \\
\hline 2010 & 109727 & 39907 & 54357 & 66999 & 466056 & 62031 \\
\hline 2011 & 270725 & 98461 & 134113 & 165304 & 1149880 & 153046 \\
\hline 2012 & 290412 & 105621 & 143866 & 177325 & 1233501 & 164176 \\
\hline 2013 & 311531 & 113302 & 154328 & 190220 & 1323202 & 176115 \\
\hline
\end{tabular}


Table 1 Continued.

\begin{tabular}{|c|c|c|c|c|c|c|}
\hline Year & Karbala & Wasit & $\begin{array}{c}\text { Salah } \\
\text { Al-Deen }\end{array}$ & Najaf & Qadisiya & Muthana \\
\hline 2007 & 24680 & 23289 & 36330 & 25038 & 14940 & 11734 \\
\hline 2008 & 26538 & 25041 & 39064 & 26923 & 16065 & 12617 \\
\hline 2009 & 28535 & 26926 & 42004 & 28949 & 17274 & 13567 \\
\hline 2010 & 30683 & 28953 & 45166 & 31128 & 18574 & 14588 \\
\hline 2011 & 75703 & 71435 & 111436 & 76801 & 45827 & 35992 \\
\hline 2012 & 81208 & 76629 & 119540 & 82386 & 49159 & 38610 \\
\hline 2013 & 87114 & 82202 & 128233 & 88377 & 52734 & 41417 \\
\hline & Thi-Qar & Maysan & Basrah & Dohouk & Sulaimaniya & Erbil \\
\hline 2007 & 24091 & 15193 & 56514 & 17545 & 13947 & 86536 \\
\hline 2008 & 25905 & 16337 & 60768 & 28919 & 21794 & 142044 \\
\hline 2009 & 27854 & 17567 & 65342 & 41758 & 34092 & 199248 \\
\hline 2010 & 29951 & 18889 & 70260 & 72478 & 86982 & 286077 \\
\hline 2011 & 73897 & 46604 & 173350 & 100121 & 138055 & 448687 \\
\hline 2012 & 79271 & 49993 & 185956 & 145175 & 220887 & 605727 \\
\hline 2013 & 85035 & 53629 & 199478 & 210504 & 353420 & 817732 \\
\hline & & & & & & \\
\hline
\end{tabular}

Table 2: Accumulated Automobile Profile classified according to fuel type.

\begin{tabular}{|c|c|c|c|c|c|c|c|}
\hline $\begin{array}{c}\text { Types of } \\
\text { Automobiles }\end{array}$ & 2007 & 2008 & 2009 & 2010 & 2011 & 2012 & 2013 \\
\hline $\begin{array}{c}\text { Gasoline } \\
\text { Automobiles }\end{array}$ & 873410 & 995654 & 1127133 & 1334866 & 2931605 & 3342315 & 3870077 \\
\hline $\begin{array}{c}\text { Gasoil } \\
\text { Automobiles }\end{array}$ & 119170 & 137482 & 159125 & 197941 & 437831 & 507127 & 598496 \\
\hline
\end{tabular}




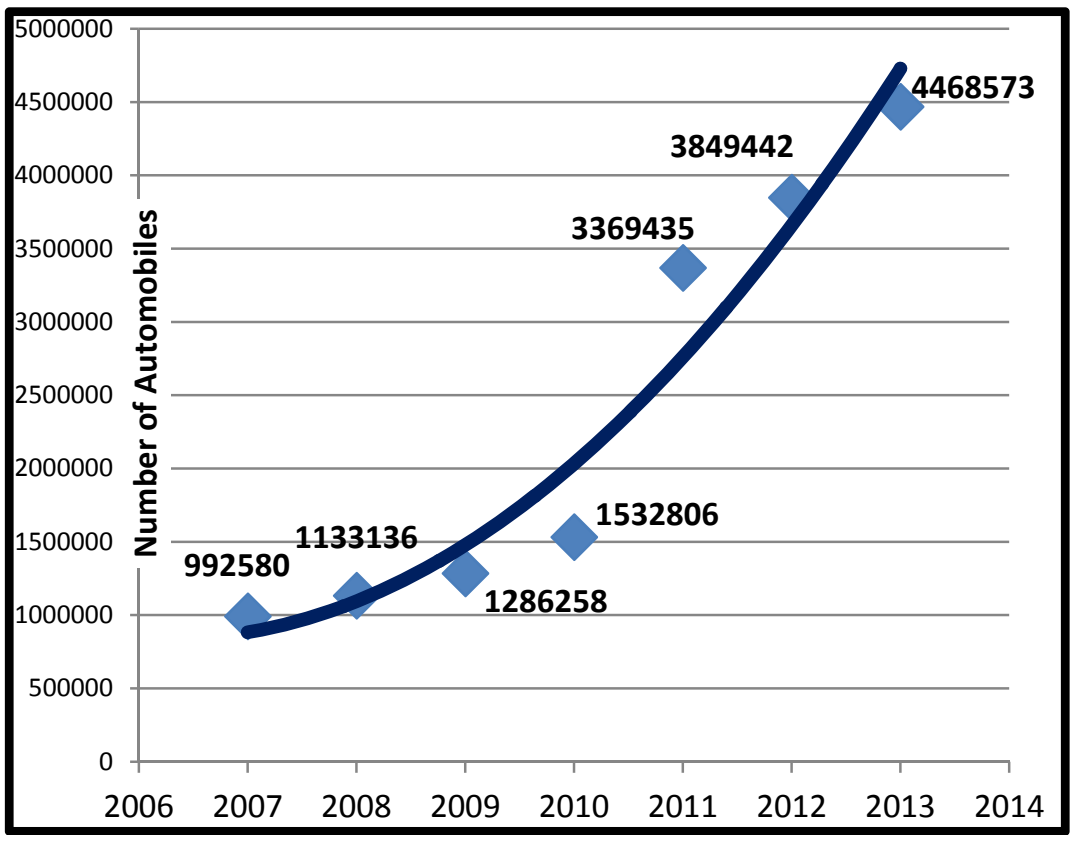

Figure 1: Accumulated automobiles profile through the period from 2007-2013.

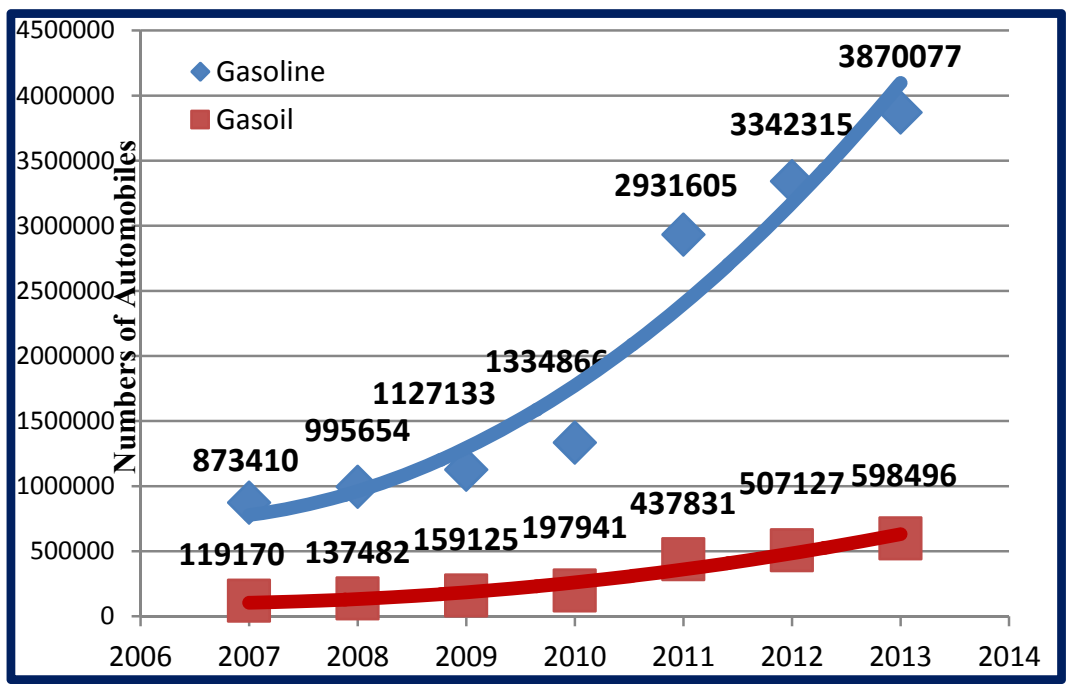

Figure 2: Accumulated automobiles profile classified according to fuel type through the period from 2007-2013. 


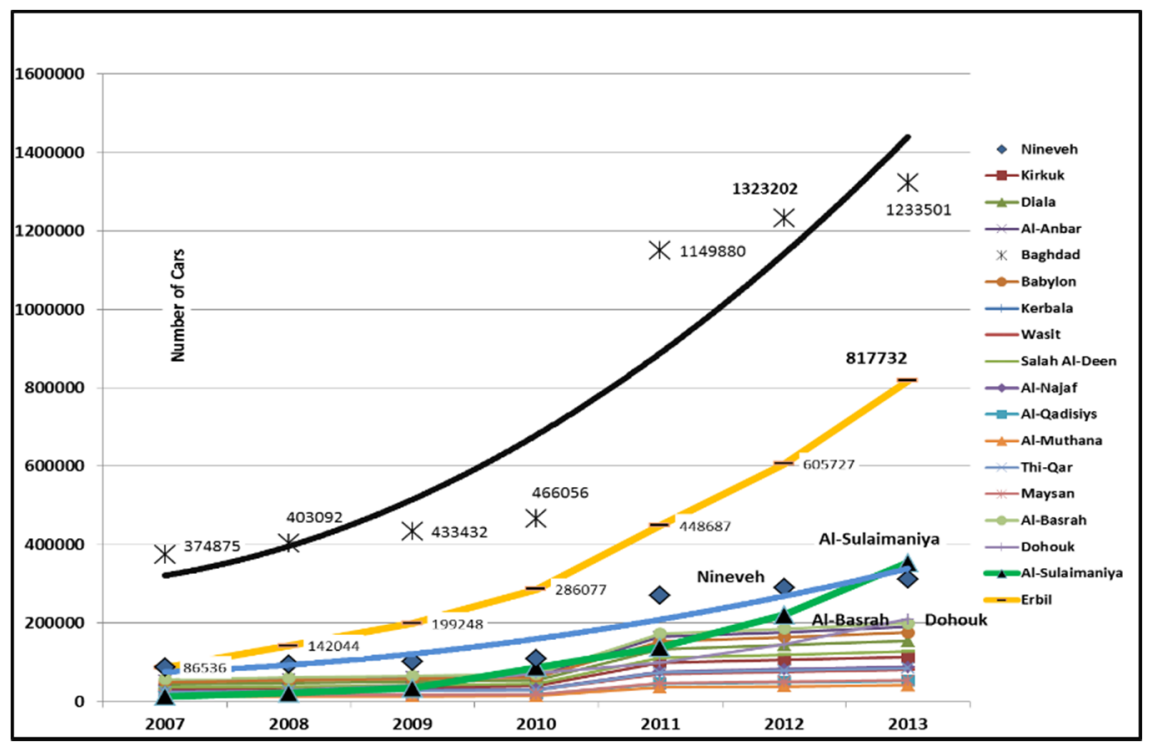

Figure 3: Accumulated automobile profile in Iraqi governorates through the period from 2007-2013.

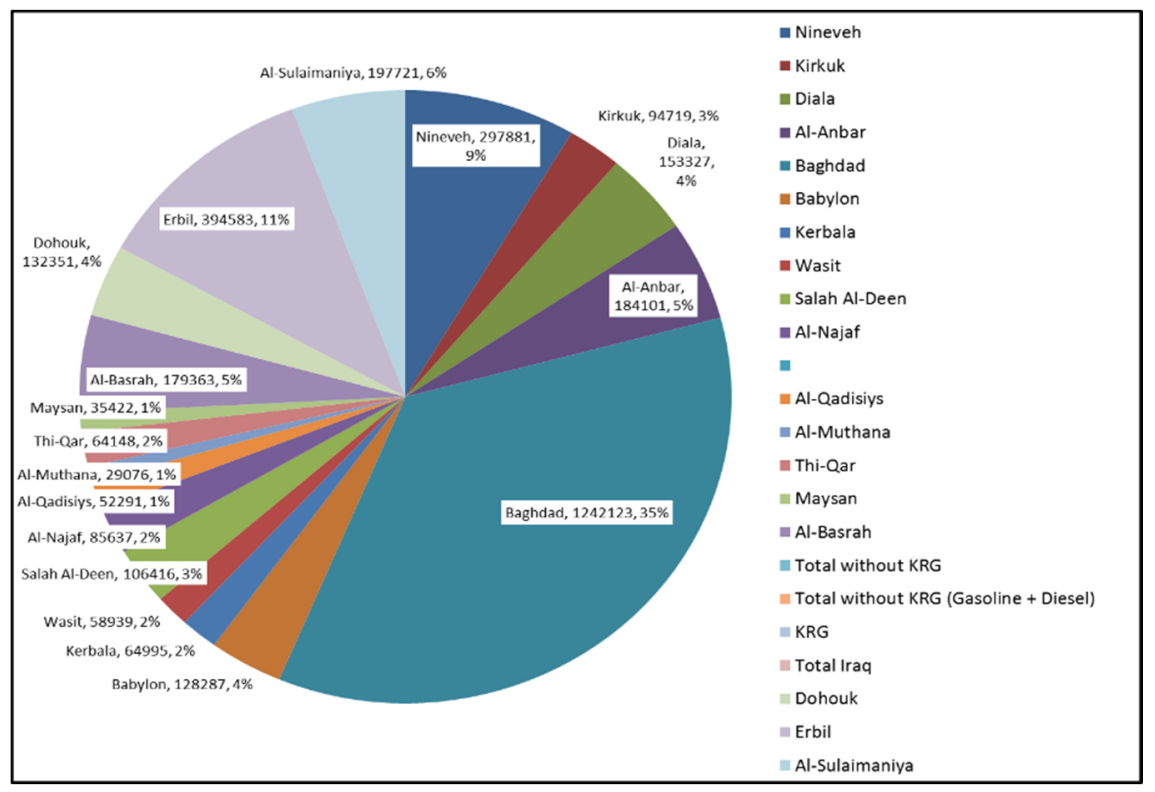

Figure 4: Automobile distribution profile in Iraqi governorates in 2013. 


\section{Rate of increasing pollutants from automobiles:}

The emission standards of different pollutants from different vehicles are as follows:

Table 3: Standard Emission $(\mathrm{mg} / \mathrm{km})$ from gasoline and gasoil fuelled vehicles [6].

\begin{tabular}{|c|c|c|c|c|c|}
\hline Types of automobiles & $\mathrm{CO}$ & $\mathrm{HC}$ & NOx & $\mathrm{CO} 2$ & $\begin{array}{c}\text { Mass Particulate MP } \\
(\mathrm{Pm})(\mathrm{PPM})\end{array}$ \\
\hline Gasoline cars & 27.7 & 3.24 & 2.04 & 399 & 0 \\
\hline Diesel passenger cars & 0.83 & 0.27 & 0.9 & 403 & 2.46 \\
\hline Diesel light & 0.94 & 0.39 & 1.01 & 537 & 2.46 \\
\hline Average diesel cars & 0.885 & 0.330 & 0.955 & 470 & 2.460 \\
\hline
\end{tabular}

Table 4: Total Automobile Gas Emissions in Iraq (2007-2013) in tons/day.

\begin{tabular}{|c|c|c|c|c|c|}
\hline Year & $\mathrm{CO}$ & $\mathrm{CO}_{2}$ & $\mathrm{HC}$ & $\mathrm{NO}_{x}$ & $\mathrm{MP}(\mathrm{PPM})$ \\
\hline 2007 & 364 & 6068 & 43 & 28 & 5 \\
\hline 2008 & 414 & 6928 & 49 & 32 & 6 \\
\hline 2009 & 468 & 7868 & 56 & 37 & 7 \\
\hline 2010 & 553 & 9385 & 66 & 44 & 8 \\
\hline 2011 & 1187 & 20632 & 145 & 96 & 18 \\
\hline 2012 & 1355 & 23579 & 165 & 110 & 21 \\
\hline 2013 & 1571 & 27382 & 191 & 127 & 24 \\
\hline
\end{tabular}

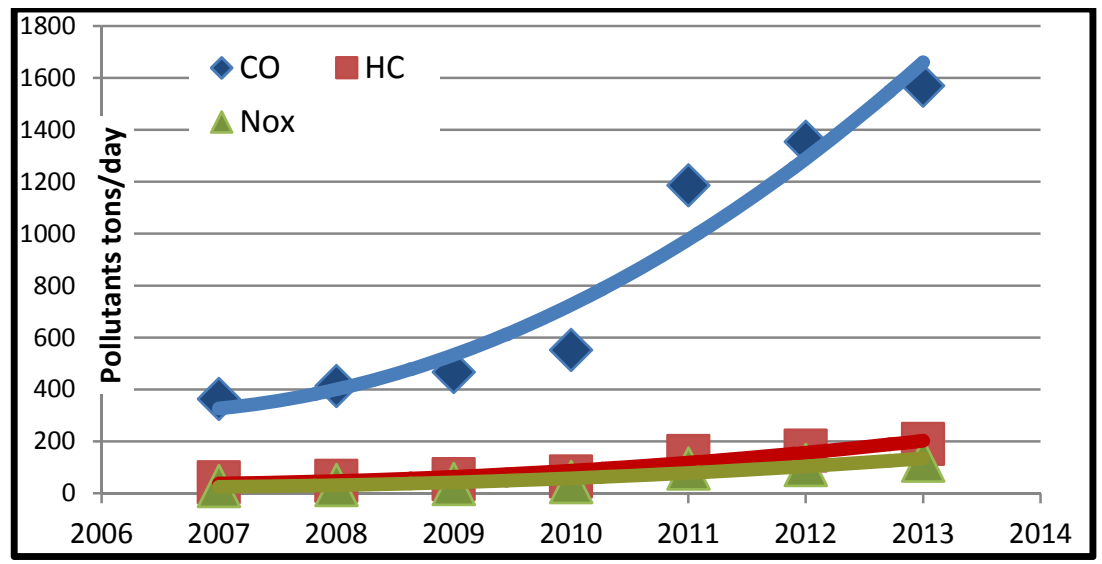

Figure 5: Rate of Pollutants emitted from different types of automobiles excluding CO2 from 2007-2013. 


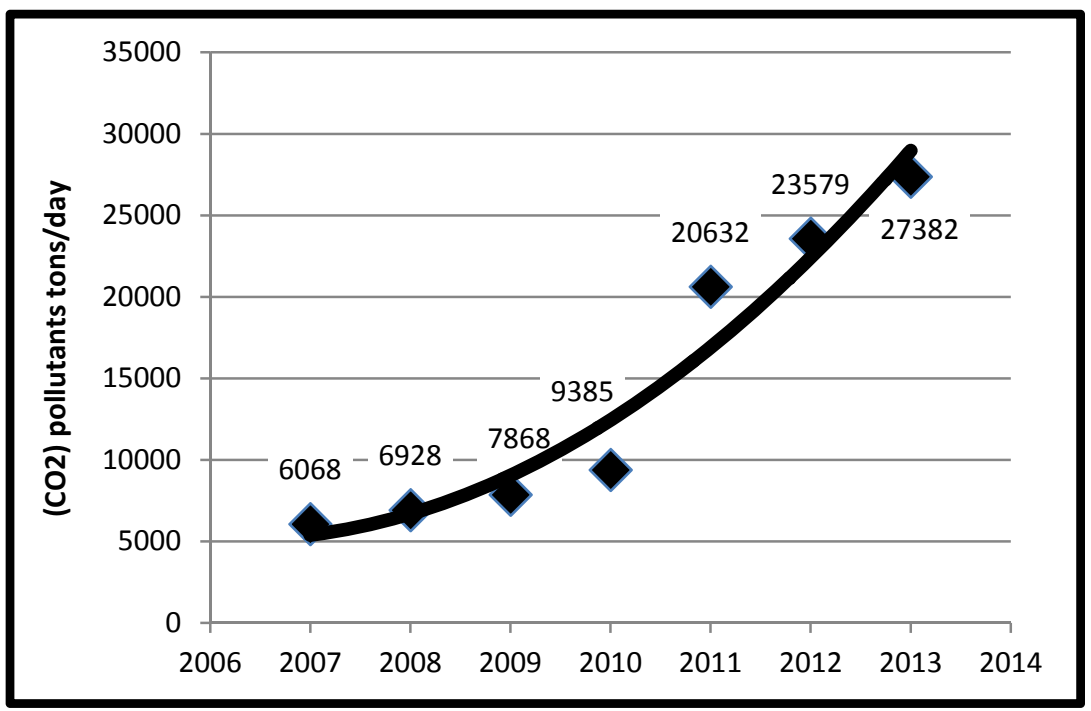

Figure 6: Rate of carbon dioxide $\left(\mathrm{CO}_{2}\right)$ pollutant emitted from different automobile types from 2007-2013.

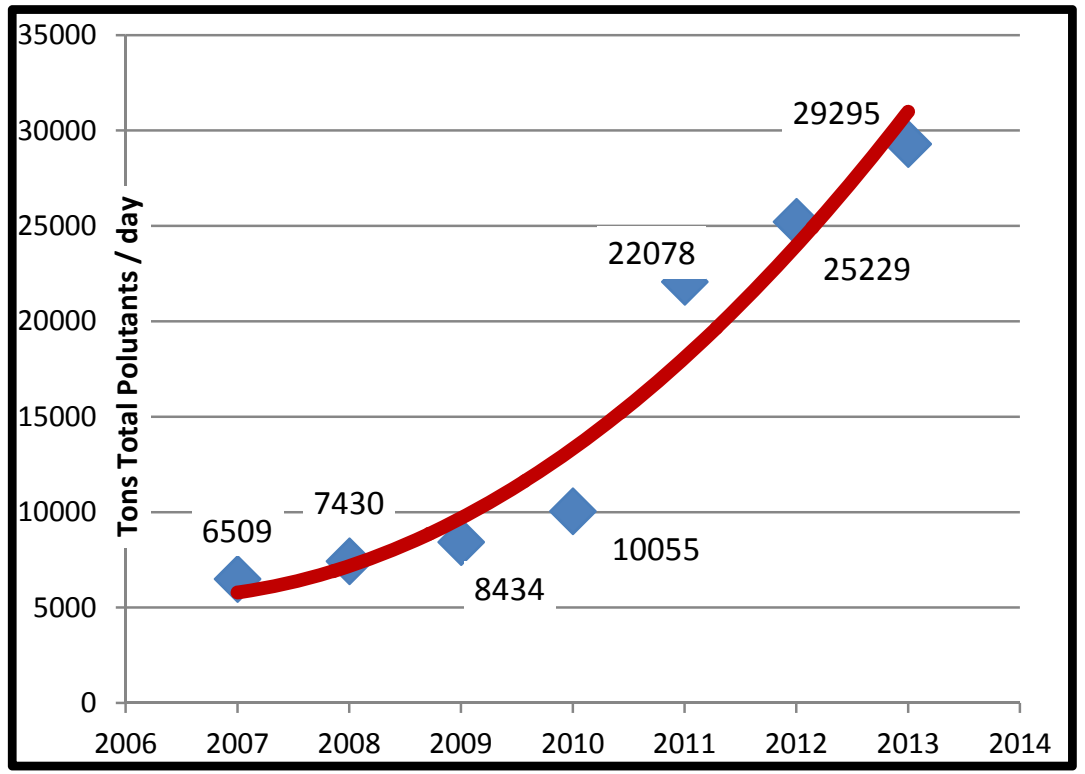

Figure 7: Rate of total pollutants emitted (tons/day) from different automobiles from 2007-2013. 


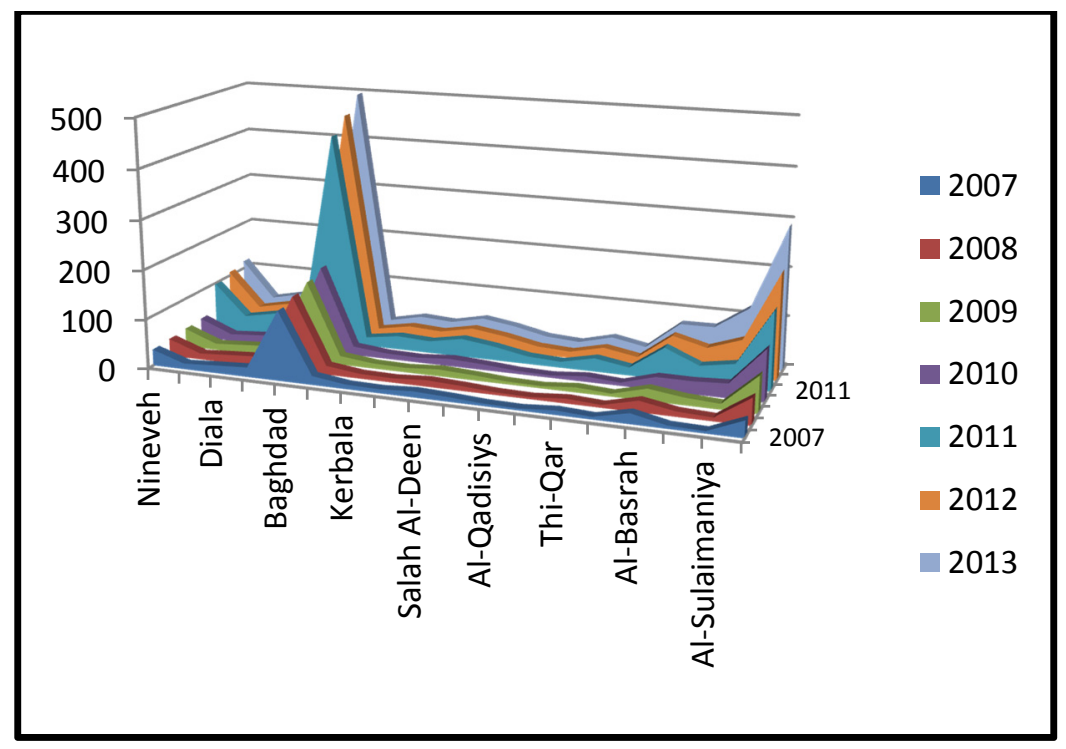

Figure 8: Rate of $\mathrm{CO}_{2}$ pollutant emitted (tons/day) from different automobiles distributed over all Iraqi governorates from 2007-2013.

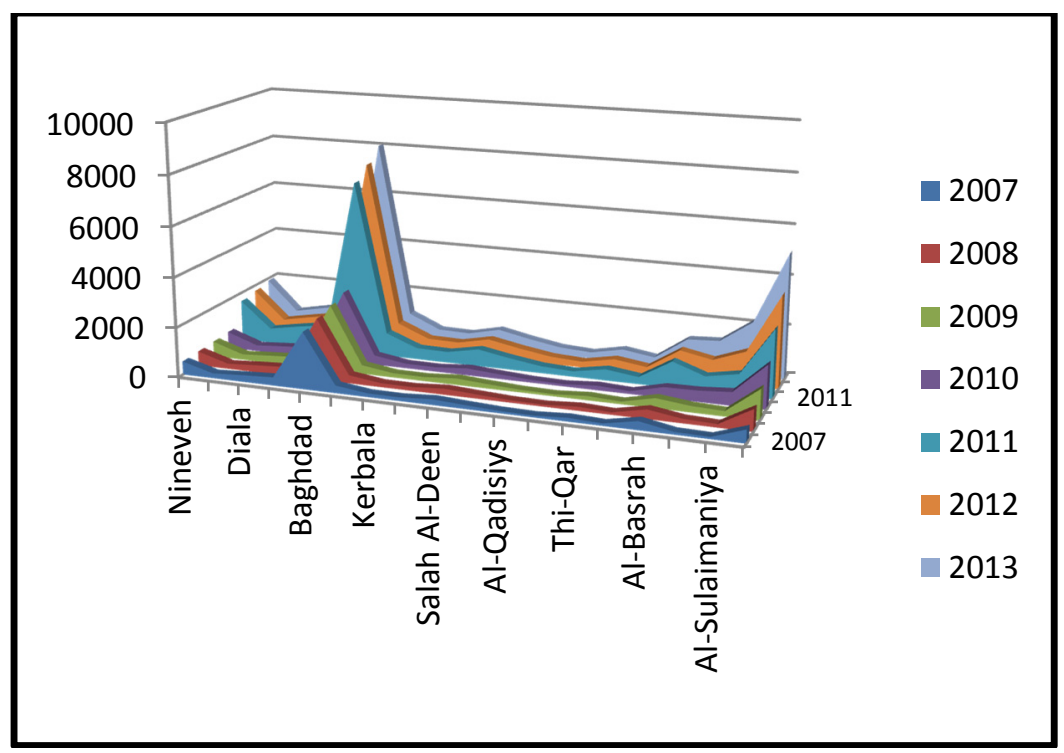

Figure 9: Rate of $\mathrm{CO}_{2}$ pollutant emitted (tons/day) from different automobiles distributed over all Iraqi governorates from 2007-2013. 


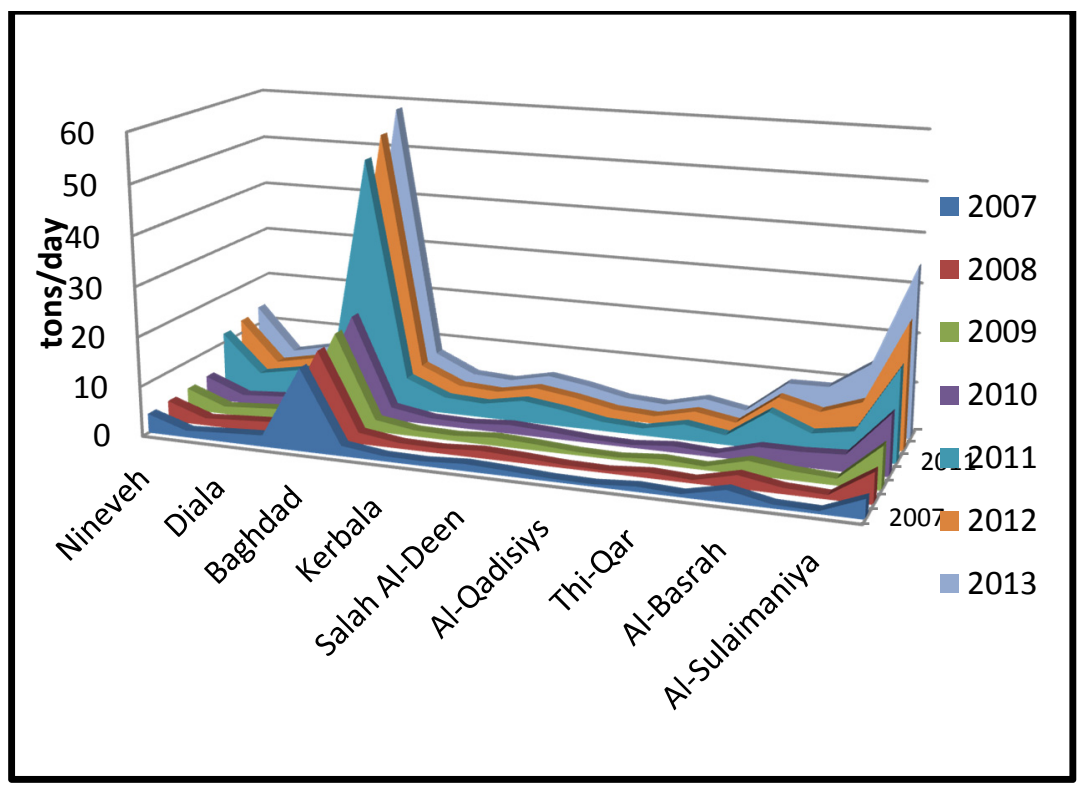

Figure 10: Rate of HC pollutants emitted (tons/day) from different automobiles distributed over all Iraqi governorates from 2007-2013.

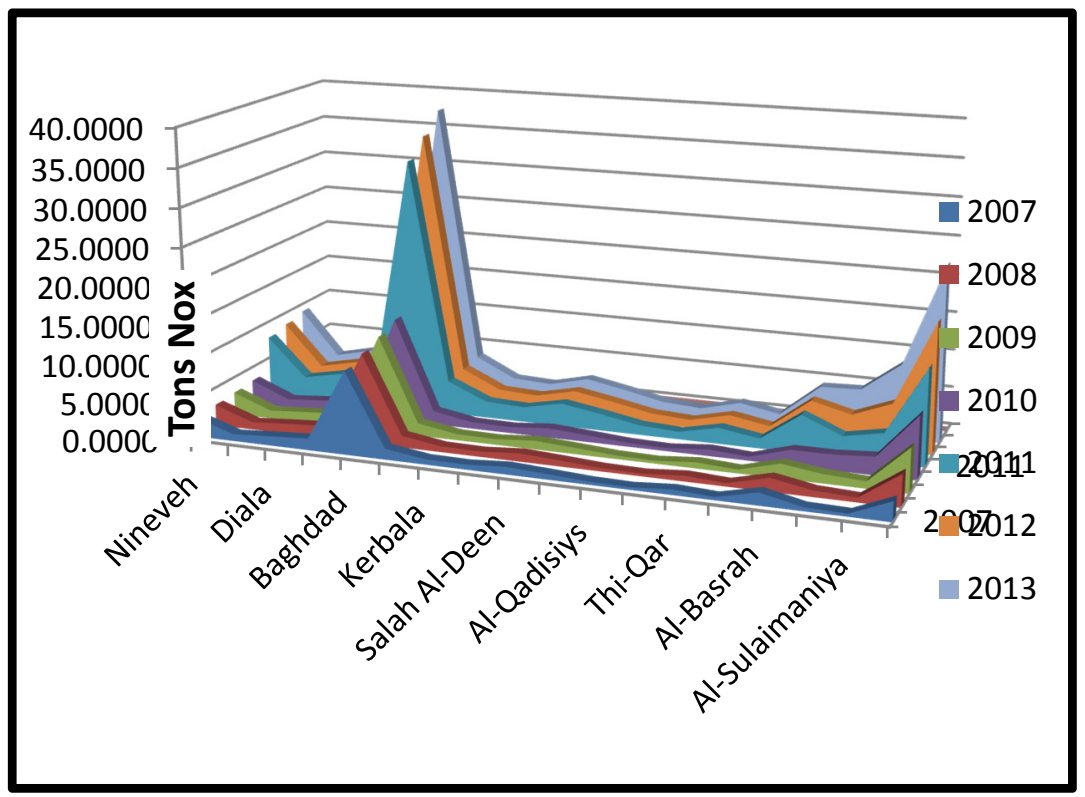

Figure 11: Rate of NOx pollutants emitted (tons/day) from different automobiles distributed over all Iraqi governorates from 2007-2013. 


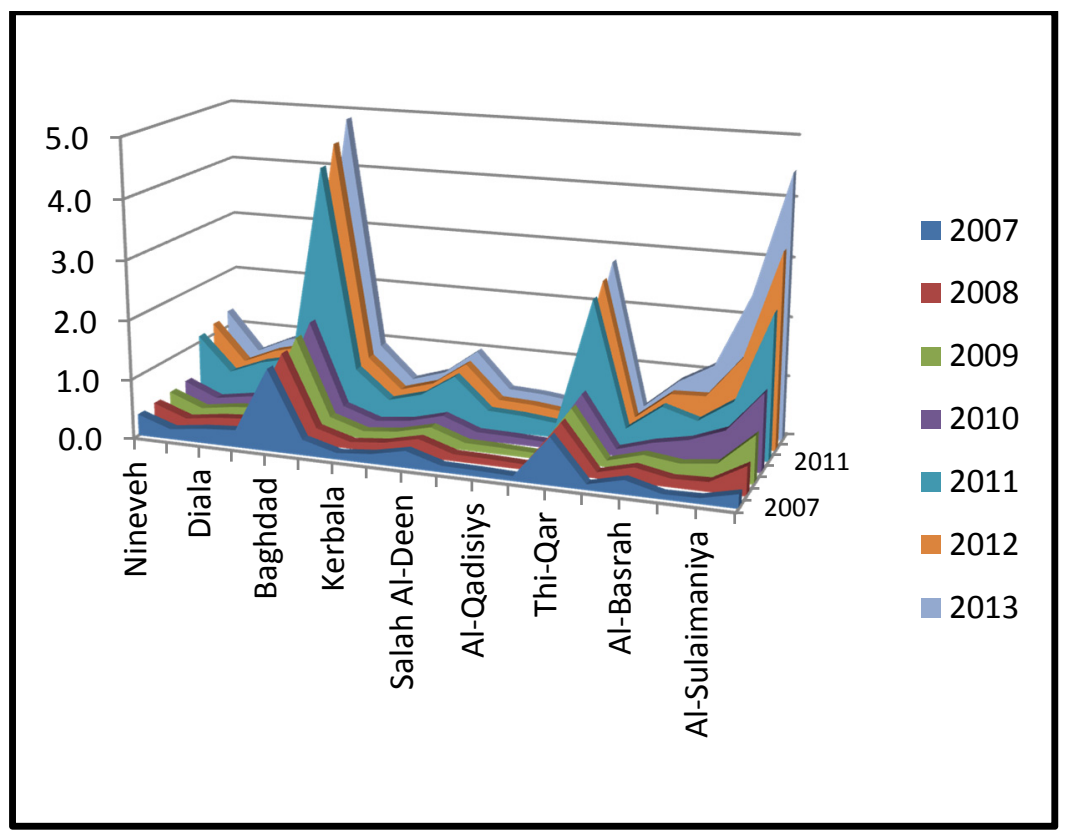

Figure 12: Rate of mass particulate pollutants emitted (tons/day) from different automobiles distributed over all Iraqi governorates from 2007-2013.

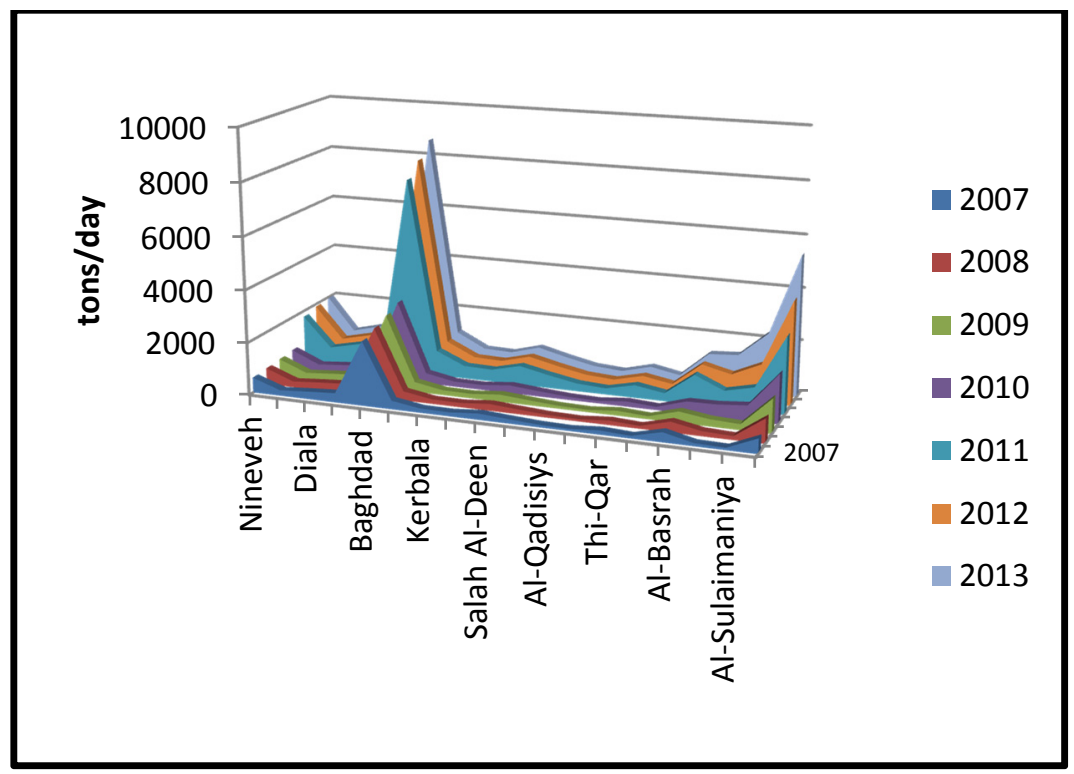

Figure 13: Rate of total pollutants emitted (tons/day) from different automobiles distributed over all Iraqi governorates from 2007-2013. 


\section{Conclusions}

The following conclusions can be made:

1. Iraq has witnessed an explosion in the imported and used numbers of vehicles during the past few years leaving a big impact on the environment. Our research has shown an increase in the production of pollutants due to the increase in the number of vehicles by an amount of 4.5 times between the years 2007 and 2013. This overall increase in the pollution rate can be broken down into the following pollutants:

2. Carbon Monoxide (CO) quantities have increased by an amount of 4.3 times between 2007 and 2013, whereby the total daily amount produced in 2013 was 1571 tons.

3. Hydrocarbons (HC) quantities have increased by an amount of 4.44 times over the same period, whereby the total daily amount produced in 2013 was 191 tons.

4. Nitrogen Oxides $\left(\mathrm{NO}_{\mathrm{x}}\right)$ quantities have increased by an amount of 4.54 times over the same period, whereby the total daily amount produced in 2013 was 127 tons.

5. Mass particulate quantities have increased by an amount of 4.8 times over the same period, whereby the total daily amount produced in 2013 was 24 tons.

6. Carbon Dioxide $\left(\mathrm{CO}_{2}\right)$ quantities have increased by an amount of 4.5 times over the same period, whereby the total daily amount produced in 2013 has reached a staggering figure of 27382 tons.

7. The noise produced associated with the increased numbers of automobiles will basically lead to the production of more noise hazards.

\section{Recommendations}

The following recommendations can be suggested:

1. Establishing an efficient cooperation between environmental organizations and the companies which are involved in the importing of automobiles looking for limited exhaust polluting gases.

2. Green belts have to be planted around the cities in Iraq with emphasis on increasing the green areas inside the cities with higher populations in order to improve the environmental conditions.

3. A close collaboration and better cooperation between the ministry of environment and other ministries, institutions, universities, research centres and hospitals has to be established for the purpose of improving the environment in Iraq.

4. Establishing a big and an efficient environmental protection programme and encouraging scientific studies and researches in the field of environmental protection and increasing the budget which is allocated for such purposes and organizing more seminars, workshops and international conferences on the environment in Iraq. 
5. Taking more care of the forests which cool down and clean up the air and add moisture in addition to maintaining an ecological balance in the country.

6. Extra care must be taken regarding more research on the winds and sand storms which transfer the pollutants from desert areas to the cities and from polluted areas to residential compounds.

\section{References}

[1] Aybars Co., Kar Co., Seyhan Co., "Environmental Protection \& Pollution Control Measures", Report, July 2010.

[2] N. N. Basak, Environmental Engineering, Fourth Reprint by Tata McGrawhill, New Delhi, 2007.

[3] Michael Allaby, Basics of Environmental Science, 2nd. Edition, Published by Taylor \& Francis, New York, 2002.

[4] Nemerow Nelson L. Agardy Franklin J., Salvato Joseph A., Environmental Engineering, Water, Wastewater, Soil and Groundwater Treatment and Remediation, Wiley Vch., Hardcover, Germany, 2009.

[5] Exports report for 2012, Republic of Iraq - Ministry of Planning, Central Statistical Organization, Directorate of Trade Statistics. April 2013.

[6] Asif Faiz, Christopher S. Weaver, Michael P. Walsh; Air Pollution from motor vehicles, p. 37-41, Washington D.C.,USA, 1996.

[7] Hamed M. Jassim, Yousif A. A. Kurdi, Fakhri H. I. Al-Nidai, Environmental Issues in Erbil City, Int. Journal Eng. Trends \& Technology (IJETT), Volume 4, Issue 8 - August 2013.

[8] Hamed M. Jassim, Yousif A. A. Kurdi, Fakhri H. I. Al-Nidai, Pollution Issues in Iraqi Kurdistan Region, Int. Journal Eng. Trends \& Technology (IJETT), Volume 4, Issue 4 - May 2013. 